\title{
"Bring a Kid to Lab Day" Features Slime Creatures and a Shape Memory Alloy
}

In an effort to encourage children from ages 3-11 to "think" about materials and possibly choose a materials science field as a career, my colleagues and I in the Chemistry Department at FultonMontgomery Community College in Johnstown, New York coordinate an annual "Bring a Kid to Lab Day." For the younger children, we make slime creatures and for the older group we feature a shape memory alloy demonstration.

For this popular event, we invite the younger children from a nearby day-care facility to spend about two hours in our laboratories. A fun time of year to hold the event is near Halloween as the children don white lab coats. We first walk the children through the chemistry laboratory which is "decorated" with many bottles of colored solutions in elaborate glassware. We have some molecular models on display and encourage the children to create some of their own. We imagine that some of the long "monster" molecules could be the drugs of tomorrow to combat diseases. We then introduce the children to "slime" made from a solution of Elmer's glue and Borateem detergent. The children each choose the color of the slime creature they wish to create and give the creature a name. Purple tends to be the most favored color, made by adding blue and red food coloring to the mixture. We explain that slime is a member of the poly-

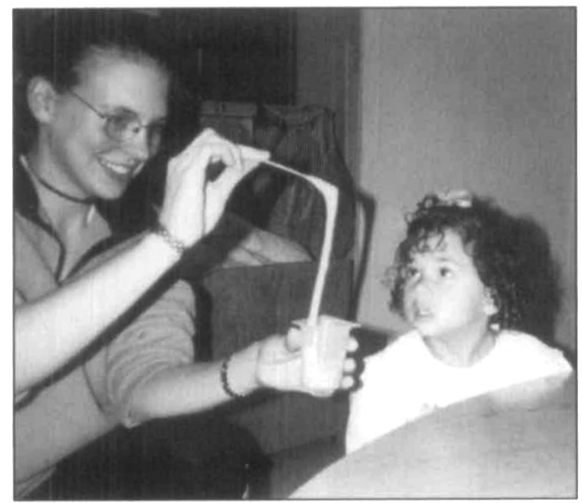

A scientist in the Chemistry Department at Fulton-Montgomery Community College in Johnstown, New York shows a child from a nearby nursery how to make slime during the department's annual "Bring a Kid to Lab Day" event.

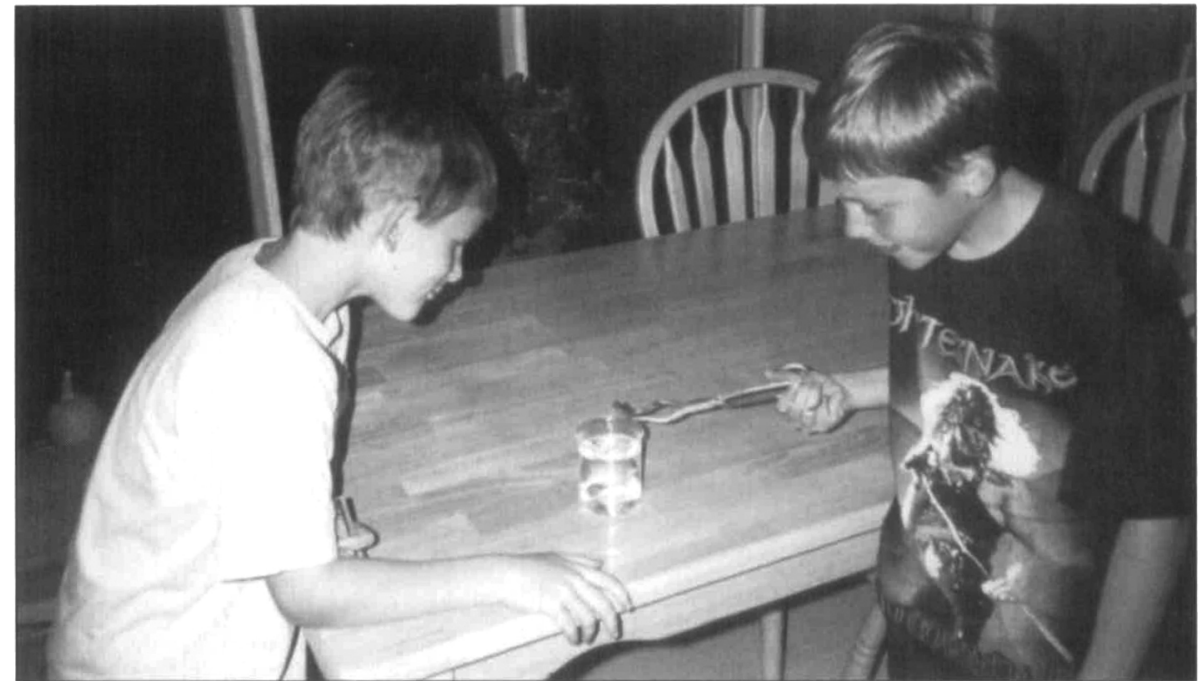

Students from elementary school experiment with a shape-memory nitinol spring to determine at what temperature the alloy loses its "memory."

mer family, and we show the children other items created from polymers.

For slightly older students, in elementary grades 3-6, we demonstrate the shape memory alloy. This is best done with a nitinol spring. We extend the spring until we decide it is worthless, then let it recoil quickly back to its original form. As this astonishes the audience, we again, with great deliberation, twist and distort and re-extend the spring until we are "sure" that we have ruined it. After immersing the spring in hot water, it recoils again. Now that the children are thoroughly fascinated, we walk them through a small experiment to determine the lowest temperature at which the nitinol "remembers" its shape.

The experiment requires a $500 \mathrm{ml}$ beaker, tongs, a thermometer, a heat source, and ice cubes. The students begin with water at $80^{\circ} \mathrm{C}$. They extend the nitinol spring and place it in the water, recording that the spring recoils quickly. They place ice cubes in the water to lower the temperature to $70^{\circ} \mathrm{C}$ and again test the nitinol for spring-back capability. They continue to lower the temperature in increments of 10 then 5 degrees until the nitinol "loses" its memory.

We conclude the visit by assisting the students in writing a "lab report." They seem to enjoy the experience of mimicking what "real scientists" do and, we hope, will pocket that memory with their nitinol spring.

JANE SLEZAK

Jane Slezak is an associate professor of chemistry at Fulton-Montgomery Community College. She has $a$ BS and MS degree in mathematics from the State University of New York at Albany and a PhD degree in chemistry from Rensselaer Polytechnic Institute. She has done postdoctoral work in quantum chemistry, statistical analysis, and biomedical engineering.

Education Exchange highlights experiences of scientists and engineers with local schools (K-12), community programs, and university programs, along with helpful hints and resources. If you would like to share your own involvement in science education, contact MRS Bulletin, Materials Research Society, 506 Keystone Drive, Warrendale, PA 15086-7573 USA; fax 724-779-8313; e-mail Bulletin@mrs.org.
Materials MicroWorld 